\title{
Gen X and Gen Y Women Managers: Challenges and Issues
}

${ }^{\text {"1 }}$ Prof. Kanchan Tolani, ${ }^{2}$ Prof. Pritam Bhadade, ${ }^{3}$ Dr. Ruchi Sao

${ }^{*}, 2,3$ Assistant Professor, Shri Ramdeobaba College of Engineering and Management, Nagpur

Email: tolanik1@rknec.edu,bhadadepr1@rknec.edu,saorn@rknec.edu

\section{Received: $20^{\text {th }}$ September 2018, Accepted: $11^{\text {th }}$ October 2018, Published: $31^{\text {st }}$ October 2018}

\begin{abstract}
Despite of increase in diversity and equality at workplace, women in India still face gender bias and are represented less at boardroom level. According to an annual survey by Grant Thornton (2017), India ranks third lowest in the proportion of business leadership roles held by women. Women experience gender stereotyping at workplace not only by men but also by other women. Though gender roles in India are changing, women in top positions are still facing various hindrances. As women constitute a large proportion of employees in several countries, awareness of the factors and barriers affecting their participation is highly required (Burrell et al, 1997). In this paper an attempt has been made to study the various challenges faced by women in managerial position. Several studies have been conducted on challenges faced by Women and how it impacts women in different settings but very few studies have focused on the role of generation as a mediating factor for the challenges faced by women on a day to day basis. Thus study compares the issues faced by Gen X and Gen Y women managers. Women managers belonging to banking sector are considered for this study. Findings reveal that there is no significant difference in the issues faced by Gen $\mathrm{X}$ and Gen Y women managers in banking sector in Nagpur. It was also found that organizational policies and workplace ecosystem majorly create hindrances for women in managerial positions.
\end{abstract}

\section{Keywords \\ Women Managers, Gen X, Gen Y, Social \& Cultural Barriers, Challenges \& Issues}

\section{Introduction}

Women experience gender stereotyping at workplace not only by men but also by other women. Despite of increase in diversity and equality at workplace, women in India still face gender bias and are represented less at boardroom level. According to an annual survey by Grant Thornton (2017), India ranks third lowest in the proportion of business leadership roles held by women. Though gender roles in India are changing, women in top positions are still facing various hindrances.

According to Rafaeli and Dutton (1997), in organizations a clear distinctions exists in terms of what is considered to be appropriate for those in management positions as opposed to non-management positions. Thus this study focuses on women acquiring leadership or management positions in an organization.

As women constitute a large proportion of employees in several countries, awareness of the factors and barriers affecting their participation is highly required (Burrell et al., 1997). Females' failure in surviving in top positions is not restricted to one industry but theses restraining stereotypes of females' exist everywhere. In response to these barriers and challenges various strategies have been implemented to help women managers at both the firm- and industry-levels. For example, various initiatives such as employment equity and diversity policies, maternity benefits, flex-time and part-time work arrangements, diversity training etc. have been introduced. But in spite of all these efforts women in managerial positions still face various hindrances.

\section{Generations}

A generation of employees, according to Kupperschmidt (2000), consists of individuals born approximately within the same time span of two decades each. The workforce at work places can be categorized into three different groups of people. Yu, H.C. and Miller, P (2005) reported that there are baby boomers, generation X and $\mathrm{Y}$ and each generation displays a different combination of lifestyle, morals and work beliefs. Studies also suggest that there are significant differences in leadership styles of different generation employees. Also, expectations from work of employees belonging to different generations are different. Thus, in this study a comparison is made between issues faced by women belonging to generation $\mathrm{X}$ and $\mathrm{Y}$.

Several studies have been conducted on challenges faced by Women and how it impacts women in different settings. However, in this study emphasis is put on understanding problems and issues faced by new generation women mangers as women now a days are acquiring managerial positions at young age. Study focuses on the challenges and problems faced women mangers working in banking sector. The study attempts to compare the challenges faced by Gen X and Gen Y women managers.

Literature review suggest that there various types of issues and challenges that women occupying managerial positions face on a day to day basis in various organizations. According to a study by Dean Elmuti(2009), women in leadership positions experience various barriers like discrimination, family-life demands, prejudice 
and stereotyping. A similar study by Mary Pflanz(2011) revealed that almost all the women in managerial positions experience challenges based gender roles and stereotypes.

A study done by ThembelihleInnocentiaMaseko (2013) found that the obstacles to women in top positions include not only the internal factors but also the external factors like social and cultural stereotypes. One of the significant constraining factor to the growth of women in managerial position is the lack of networking of women. Women because of gender roles miss out on various informal networking opportunities and this acts as an obstacle to the growth of women in organizations.

A research by Lan $\mathrm{Li}(2001)$ reveals that barriers to advancement of women in managerial positions are neither the corporate practices nor the policies but are the outcomes of cultural and societal sanctions.

As many studies and researches identify barriers to women occupying managerial positions, a lot of studies have also focused on finding out the strategies which can be used to eliminate these hurdles.

A study by Dean Elmuti(2009) suggested that providing trainings to women in managerial positions can prepare women to cope up with these challenges. Mary Pflanz (2011) found that role models are significant contributors to the success and failure of women managers. It is observed in various studies that self-efficacy is also one of the important factor responsible for the success and failure of women managers. Women who are found to be high on self-efficacy tend to perform their managerial and leadership roles better.

Studies also suggest that leadership styles used by women are more beneficial for organizational effectiveness in integrating the system of reward, motivation, expectation and zeal among others (Xiao Zheng). Manisha Singh in a study found that recruiting more women in managerial positions will help organizations to take advantage of soft skills that women possess and thus will help firms in retaining their customers and employees better. Samantha C. Paustian-Underdahl (2014) suggested that when leadership is concerned, men and women do not differ in perceived leadership effectiveness. Moreover, women are rated as significantly more effective than men when it comes to being effective leaders.

Thus literature review also suggests women managers are no less than male managers. Also in various instances women leadership styles are more favorable for the growth of the organizations. Policy makers should thus give due attention to the problems and hurdles faced by women managers and necessary steps must be taken to eliminate them.

\section{Material and Methods}

This study is exploratory in nature and uses both quantitative and qualitative data for analysis. The quantitative information gained from the survey shall be analyzed using both descriptive and inferential statistics. Data was collected with the help of a structured questionnaire followed by interview of women manager.

For this study we are considering only generation $\mathrm{X}$ and $\mathrm{Y}$ as people who are born before this generation are too old so they must be retired and people who are born after generation $\mathrm{Y}$ are too young to become managers. Thus the two age groups to be studied are above age 45 and below age 45 .

There is a lot of published literature supporting the argument that women managers on a day to day basis face various challenges at workplace. In this study, an attempt is made to formulate a theoretical framework of challenges faced by Indian women managers. The study will focus at comparing the issues faced by women mangers belonging to different generation in banking sector. Women belonging to Gen $\mathrm{X}$ and Gen $\mathrm{Y}$ are considered for the study. The findings of the study will not only be of academic concern, but will also be beneficial for policy makers in identifying strategies for eliminating such barriers at workplace.

"Purposive" \& "Convenience" sampling method will be used for studying the research work. The sample size will be restricted to 100 women managers.

\section{Hypothesis}

$\mathrm{H}_{1}$ : There is a significant difference in challenges faced by women managers belonging to generation $\mathrm{X} \& \mathrm{Y}$

$\mathrm{H}_{2}$ : There is a relationship between lack of family support and challenges faced by women managers.

$\mathrm{H}_{3}$ : There is a relationship between cultural barriers and challenges faced by women managers.

$\mathrm{H}_{4}$ : There is no relationship between workplace ecosystem and challenges faced by women managers.

The research conducted on 100 women managers belong to Nagpur region. The women managers were asked to fill questionnaire consisting of 18 questions majorly focusing on issues and challenges faced by Generation X and $\mathrm{Y}$ women managers. The findings will be reported in the part of results and discussion.

\section{Results and Discussion}

This part discusses the findings in the study.

1. Factors identified which create issues for both generation managers to carry out managerial responsibilities identified were organizational policies, cultural and societal norms, lack of family support and others. Out of these, the major factor identified in the study is organizational policies as displayed in figure 1. 


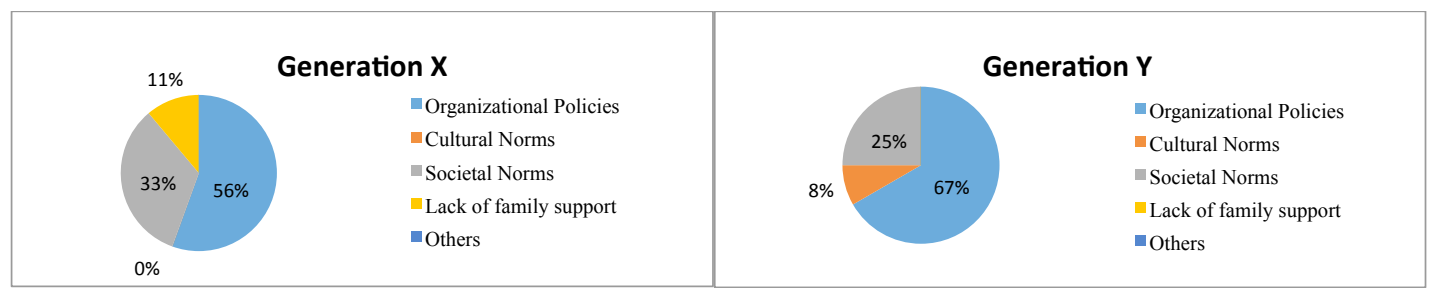

Figure 1: Factors Creating Issues for Both Generations

2. There are no different treatments at work to male and female employees occupying the similar position experienced by Generation X and Y managers. However, 33\% of Generation Y managers experienced different treatments at work to male and female. The same has been mentioned in figure 2 .

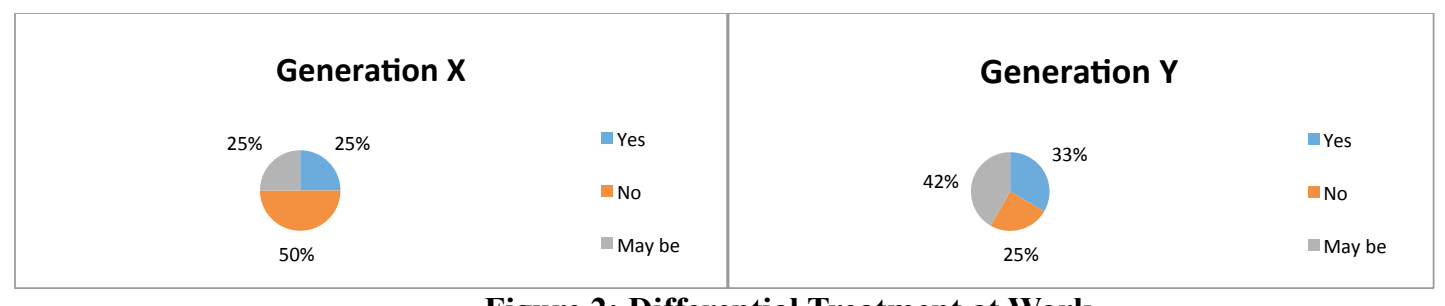

Figure 2: Differential Treatment at Work

3. According to survey, family commitments and responsibilities does not create any hindrance to the work for majority of generation $\mathrm{X}$ and $\mathrm{Y}$ women managers.

The remaining $25 \%$ from generation $\mathrm{X}$ feels caring for children is a hindrance and the remaining $25 \%$ of generation $\mathrm{Y}$ feels that marriage has disturbed their career growth. The same is reflected in figure 3.

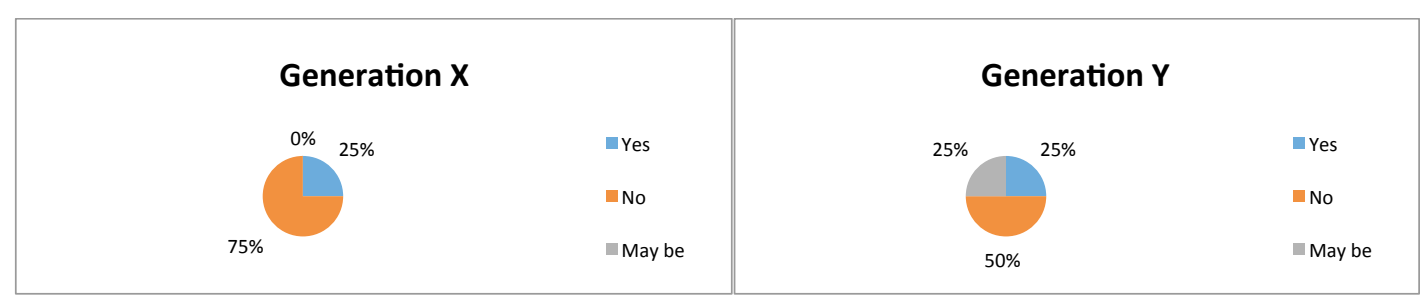

Figure 3: Factors Creating Hindrances at Work

4. Figure 4 represents generation $X$ women managers experienced instances, when their subordinates do not take your commands seriously while Generation $Y$ women managers does not experience the same.

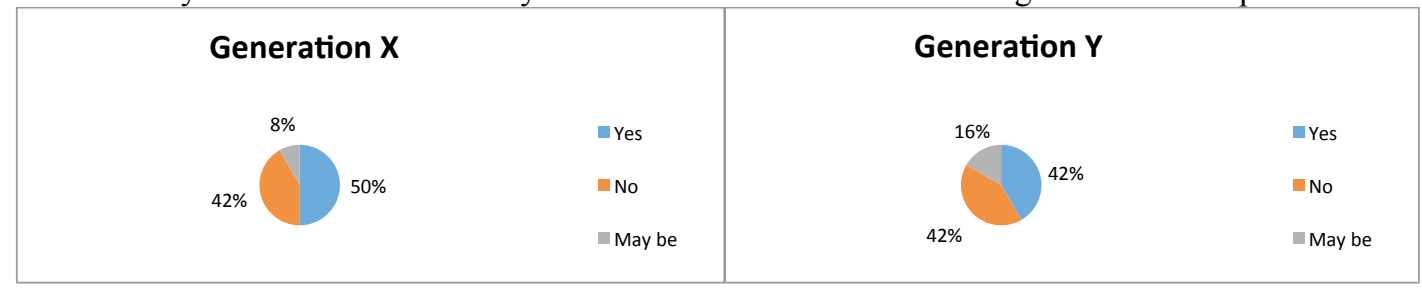

Figure 4: Data with respect to Subordinates Following Commands

5. Figure 5 represents generation $Y$ feels that the organization does not have policies which ensure work life balance for women managers while Generation $\mathrm{X}$ is neutral about the same.

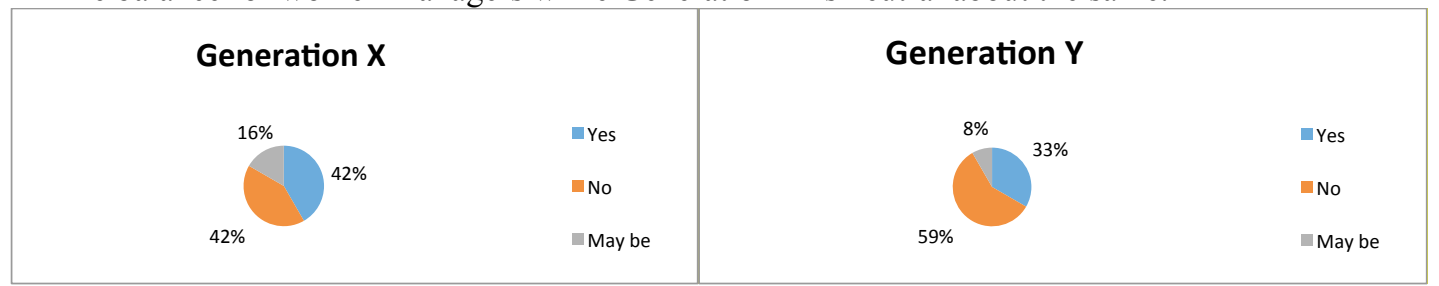

Figure 5: Data with respect to Policy for Work Life Balance

6. Majority of Generation $\mathrm{X}$ feels that people at work do not make perceptions about their character, competence, reputation in the way they like. While Majority of Generation Y feels that people at work 
make perceptions about their character, competence, reputation in the way they like and it affect their self-confidence at work. Refer figure 6 for the same.

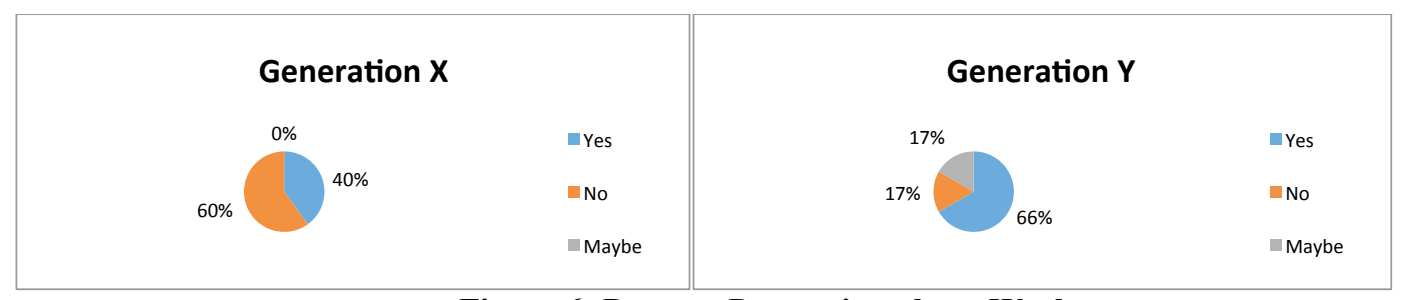

Figure 6: Data on Perception about Work

7. Figure 7 represents that majority of Generation $\mathrm{X}$ and $\mathrm{Y}$ women managers feel that work life balance is the most frequently faced problem by them at work. The other parameters like sexual harassment and others do not create much hindrance. However, in case of generation Y, $25 \%$ of respondents report that they have faced gender discrimination.

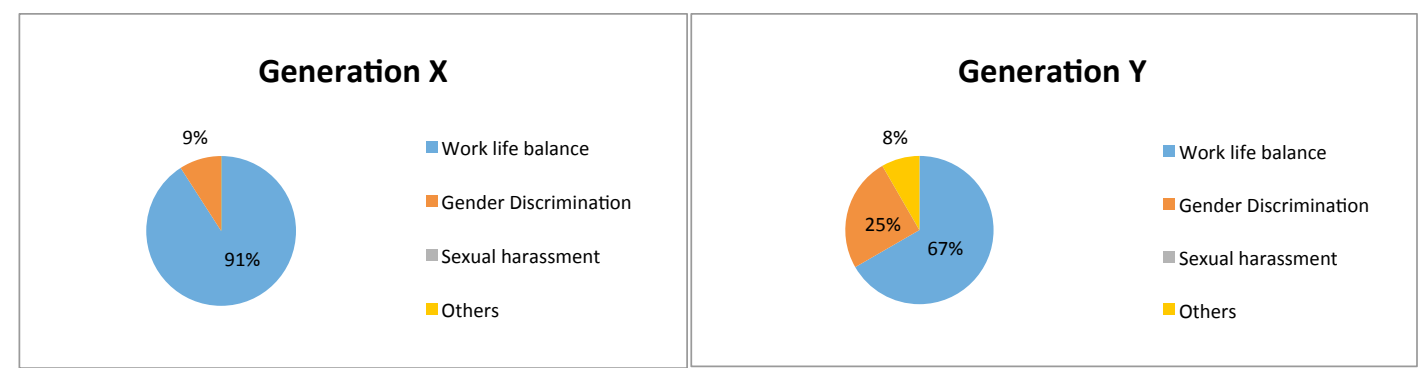

Figure 7: Data on Problems Faced by Women Managers

8. Figure 8 represents data for daily hassles and issues faced by women managers at work. Majority of Generation $\mathrm{X}$ and $\mathrm{Y}$ women managers feels that reasons which majorly create hindrance for women managers to perform their work effectively is unfair organizational policies. Others are being lack of support from colleagues or subordinates.

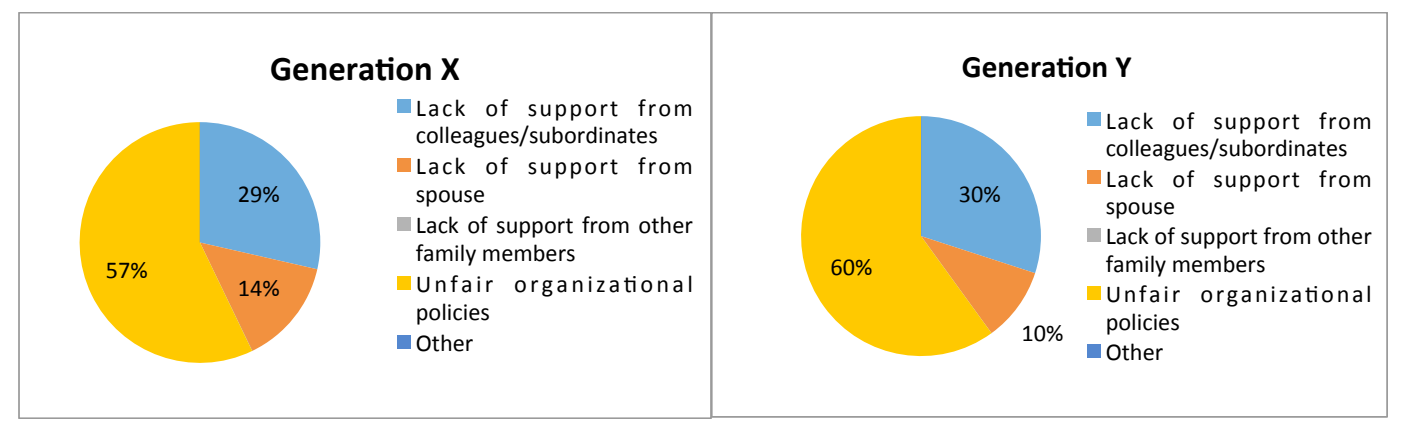

Figure 8: Data for Daily Hassles and Issues Faced by Women Managers at Work

\section{Overall Findings}

According to survey conducted the following thing can be stated about the hypothesis formulated above.

1. There is a no significant difference in challenges faced by women managers belonging to generation $\mathrm{X}$ $\& \mathrm{Y}$

2. There is a no relationship between lack of family support and challenges faced by women managers.

3. There is a no relationship between cultural barriers and challenges faced by women managers.

4. There is a relationship between workplace ecosystem and challenges faced by women managers.

\section{Conclusion}

The respondents in this study indicated that there is no difference in challenges and issues face by generation $\mathrm{X}$ and $\mathrm{Y}$ women managers. According to them unfair Organizational policies are responsible for daily hassles and issues face by them. They also feel that the organization does not have policies for work life balance. Both gen- 
eration women managers do not experienced family responsibilities and commitments creating hindrances in their work.

\section{Future Scope}

The current study focuses on identifying the issues and challenges faced by women managers working in Banking sector thus the result of the study cannot be generalized. The study creates future scope of studying the challenges faced by women managers in other sectors. Further studies can be carried out for determining various interventions and strategies which can help the women managers to overcome these challenges. Studies can be conducted across different countries and geographical locations also.

\section{References}

1) Rafaeli, A., Dutton, J., Harquail, C.V. and Mackie-Lewis, S., (1997), "Navigating by attire: The use of dress by female administrative employees", Academy of Management Journal, 40(1), pp.9-45.

2) Burrell, J., Manfredi, S., Rollin, H., Price, L. and Stead, L., 1997. Equal opportunities for women employees in the hospitality industry: a comparison between France, Italy, Spain and the UK. International Journal of Hospitality Management, 16(2), pp.161-179.

3) Elmuti, D., Jia, H. and Davis, H.H., 2009. Challenges women face in leadership positions and organizational effectiveness: An investigation. Journal of leadership education, 8(2), pp.167-186.

4) Pflanz, M., 2011. Women in positions of influence: Exploring the journeys of female community leaders.

5) Maseko, T.I., 2013. A comparative study of challenges faced by women in leadership: a case of Foskor and the Department of Labour in Mhlathuze Municipality (Doctoral dissertation, University of Zululand)

6) Li, L. and Wang Leung, R., 2001. Female managers in Asian hotels: profile and career challenges. International Journal of Contemporary Hospitality Management, 13(4), pp.189-196.

7) Yang-ran, G.O.N.G., Hao, C.H.E.N. and ZHENG, X.M., 2013. Research on the Effect of Transformational Leadership on Organizational Culture: A Case Study on China Entrepreneur Magazine [J]. Journal of Management Case Studies, 3.

8) Paustian-Underdahl, S.C., Walker, L.S. and Woehr, D.J., 2014. Gender and perceptions of leadership effectiveness: A meta-analysis of contextual moderators. Journal of applied psychology, 99(6), p.1129.

9) Appelbaum, S.H., Audet, L. and Miller, J.C., 2003. Gender and leadership? Leadership and gender? A journey through the landscape of theories. Leadership \& Organization Development Journal, 24(1), pp.4351.

10) Singh, A. and Manisha, R., 2013. Women entrepreneurs in micro, small and medium enterprises. Internafional Journal of Management and Social Sciences Research (IJMSSR), 2(8).

11) Yu, H.C. and Miller, P., 2005. Leadership style: The X Generation and Baby Boomers compared in different cultural contexts. Leadership \& Organization Development Journal, 26(1), pp.35-50. 